\title{
Erratum to: Equality in Obstetrical Care: Racial/Ethnic Variation in Group B Streptococcus Screening
}

\author{
Allison S. Bryant · Yvonne W. Cheng • \\ Aaron B. Caughey
}

Published online: 11 November 2010

(C) Springer Science+Business Media, LLC 2010

\section{Erratum to: Matern Child Health J \\ DOI 10.1007/s10995-010-0682-8}

We wish to draw your attention that we failed to include the Acknowledgment section in our article. Please find the below acknowledgment for your reference.

Acknowledgments This publication was supported by NIH/NCRR/ OD UCSF-CTSI Grant No. KL2 RR024130 (Dr. Bryant). Its contents are solely the responsibility of the authors and do not necessarily represent the official views of the NIH. Dr. Bryant is also supported by the Amos Medical Faculty Development Award of the Robert Wood Johnson Foundation, Grant No. RWJF-63524. Dr. Caughey is supported by the Robert Wood Johnson Foundation as a Physician Faculty Scholar Grant No. RWJF-61535. Dr. Cheng is supported as a Women's Reproductive Health Research Scholar at the University of California, San Francisco.

The online version of the original article can be found under doi:10.1007/s10995-010-0682-8.

\footnotetext{
A. S. Bryant $(\square)$

Department of Obstetrics and Gynecology, Massachusetts General Hospital, 55 Fruit Street, Boston, MA 02114, USA

e-mail: abryant@partners.org

Y. W. Cheng

Department of Obstetrics, Gynecology and Reproductive

Sciences, University of California, San Francisco, San Francisco,

CA, USA

A. B. Caughey

Department of Obstetrics and Gynecology, Oregon Health \&

Sciences University, Portland, OR, USA
} 